\title{
MicroRNA-125a-5p inhibits invasion and metastasis of gastric cancer cells by targeting BRMS1 expression
}

\author{
YI CAO $^{1 *}$, SHENGXING TAN $^{1 *}$, YI TU $^{2 *}$, GUOYANG ZHANG $^{1}$, YI LIU $^{1}$, DAOJIANG LI ${ }^{1}$, SHAN XU $^{2}$, \\ ZHIBIAO LE ${ }^{1}$, JIANBO XIONG ${ }^{1}$, WENYU ZOU ${ }^{1}$, PEITAO GONG ${ }^{1}$, ZHENGRONG LI ${ }^{1}$ and ZHIGANG JIE ${ }^{1}$ \\ Departments of ${ }^{1}$ General Surgery and ${ }^{2}$ Pathology, First Affiliated Hospital, \\ Nanchang University, Nanchang, Jiangxi 330006, P.R. China
}

Received October 8, 2015; Accepted September 7, 2017

DOI: $10.3892 / \mathrm{ol} .2018 .7983$

\begin{abstract}
Accumulating studies have demonstrated microRNAs (miRNAs/miRs) have an important role in multiple processes of human malignant tumor development and progression. Decreased expression of miR-125a-5p has been observed in several types of cancer, including gastric cancer (GC). However, the mechanism and exact function of miR-125a-5p in GC have not been largely elucidated. In the present study, reverse transcription-quantitative polymerase chain reaction indicated that the expression of miR-125a-5p was downregulated in GC tissues and cell lines compared with matched normal tissues $(\mathrm{P}<0.01)$ and normal gastric mucosa cell lines $(\mathrm{P}<0.01)$, respectively. Moreover, clinical pathological characteristics and Kaplan-Meier analysis indicated that a low expression of miR-125a-5p was not only associated with lymph metastasis, peritoneal dissemination and advanced tumor-node metastasis stage but also affected the prognosis of GC patients. Compared with miR-control-transfected GC cells, markedly decreased migration and invasion was observed in GC cells that overexpress miR-125a-5p. By contrast, increased metastasis and invasion were observed in miR-125a-5p-knocked down cells compared with the control. Furthermore, luciferase reporter assays indicated that breast cancer metastasis suppressor 1 (BRMS1) was a direct target of miR-125a-5p. Notably, a positive correlation between the levels of BRMS1 and miR-125a-5p in GC tissues was observed, and BRMS1 expression was indicated to be regulated by miR-125a-5p in GC cells. In conclusion, miR-125a-5p may act
\end{abstract}

Correspondence to: Professor Zhigang Jie or Professor Zhengrong Li, Department of General Surgery, First Affiliated Hospital, Nanchang University, 17 Yongwai Zheng Road, Nanchang, Jiangxi 330006, P.R. China

E-mail: jiezg123@126.com

E-mail:1zr13@foxmail.com

*Contributed equally

Key words: microRNA-125a-5p, breast cancer metastasis suppressor 1, gastric cancer, Invasion and metastasis as a tumor suppressor by targeting the metastasis-inhibitory gene, BRMS1. The data suggesting that BRMS1 is a potential target gene of miR-125a-5p, may provide novel insight into miRNA regulation of human gene expression, and a useful target for gene therapy of GC.

\section{Introduction}

Gastric cancer (GC) is a frequently diagnosed cancer among males and females worldwide, and an estimated 951,600 new stomach cancer cases and 723,100 mortalities occurred in 2012 (1). Although clinical outcome in therapy of GC has improved unceasingly through earlier diagnosis, surgical resection, chemotherapy and radiation therapy, the prognosis of patients with advanced GC remains rather poor with a five-year survival rate of $5-20 \%(2,3)$. The primary cause of mortality in GC is tumor progression and metastasis (4). Therefore, the present study aims to investigate molecular mechanisms that are involved in the development of GC and provide a novel and effective method for diagnosis or treatment.

MicroRNAs (miRNAs/miRs) are endogenous small single-stranded RNA molecules and consist of 18-23 nucleotides. It has been found that miRNAs are able to participate in the regulation of cell proliferation, differentiation, metabolism and apoptosis $(5,6)$. A large number of studies have subsequently confirmed that miRNAs are involved in the pathogenesis of a number of human diseases, including cancer (7) and diseases involving the nervous system (8). In addition, researchers have also found that miRNAs are able to regulate tumor formation, infiltration and metastasis by directly binding to the mRNA of target gene $(6,9)$. Moreover, an increasing number of studies indicated that miRNAs are involved in the metastasis and invasion of GC, including miR-34 (10), miR-19 (11), miR-29 (12,13), miR-495 (14) and miR-551a (14). Although compelling evidence from a study has indicated that miR-125a-5p was downregulated in GC (15), the specific mechanisms of miR-125a-5p in the metastasis and invasion of GC have not been largely illuminated.

Breast-cancer metastasis suppressor 1 (BRMS1) is a gene, which inhibits metastasis. First identified in 2000 (16), the gene suppresses the metastasis of breast carcinoma cells to lungs and regional lymph nodes. Subsequent studies indicated that BRMS1 mediated inhibition of metastasis in multiple types of 
human cancer, including GC (17-20). A number of studies have confirmed that a number of protein-coding genes are regulated by miR-125a-5p in different types of human cancer $(21,22)$. However, the associations between BRMS1 and miR-125a-5p in GC have not been fully revealed.

In the present study, a low expression of miR-125a-5p was frequently observed in GC tissues and cell lines, and a low miR-125a-5p expression was associated the prognosis of patients with GC. It has also been demonstrated that miR-125a-5p expression may affect the invasion and migration of GC cells in vitro. Based on findings from bioinformatics analysis using online tools, BRMS1 was identified as a potential target gene of miR-125a-5p. The experiments demonstrated that miR-125a-5p is able to regulate the expression of BRMS1 expression in GC cells, which may lead to further advancements in the knowledge of GC tumorigenesis.

\section{Materials and methods}

Ethics statement. The present study was approved by the Ethics Board of the Institute of the First Affiliated Hospital of Nanchang University (Nanchang, China). The ethics board also supervised and examined the whole process of the present study. All participants agreed to join the present study and provided written informed consent.

Gastric tissues samples. Cancer tissue samples and matched normal samples (distance from tumor, $\geq 5 \mathrm{~cm}$ ) were obtained from $82 \mathrm{GC}$ patients (43 males and 39 females; mean age, 58.3 years, age range, 33-85) who underwent surgical resection from February 2010 to November 2012 at the Department of General Surgery, First Affiliated Hospital of Nanchang University (Nanchang, China). The samples were immediately stored in liquid nitrogen following removal from patients and detailed clinical data were collected. The histological grade was assessed according to the tumor-node-metastasis (TNM) system (23), established by the Union for International Cancer Control. All patients were monitored every 3 months. The follow-up period ranged from 2 to 80 months (mean duration, 24.5 months). None of the patients received any additional treatment prior to surgery.

Cell lines and cell culture. Human GC cell lines (SGC7901, HGC27 and BGC823) were purchased from the Type Culture Collection of the Chinese Academy of Sciences (Shanghai, China). The human gastric mucosa GES1 and HFE145 cell lines were stored in the Central Laboratory of the Center for Experimental Medicine, the First Affiliated Hospital of Nanchang University, Nanchang, China), which were obtained from American Type Culture Collection (Manassas, MA, USA). All cell lines were cultured in Dulbecco's modified Eagle's medium (Invitrogen; Thermo Fisher Scientific, Inc., Waltham, MA, USA) supplemented with $10 \%$ fetal bovine serum (Invitrogen; Thermo Fisher Scientific, Inc.) and $100 \mathrm{U} / \mathrm{ml}$ penicillin at $37^{\circ} \mathrm{C}$ with $5 \% \mathrm{CO}_{2}$. The cells in the exponential phrase were used for experiments.

$R N A$ extraction and reverse transcription-quantitative polymerase chain reaction $(R T-q P C R)$. Total RNA was extracted from cells or tissues using a standard Trizol protocol (Invitrogen; Thermo Fisher Scientific, Inc.). To detect the expression of mRNAs, reverse transcription was conducted using the GoScriptTM Reverse Transcription system (Promega Corporation, Madison, WI, USA) according to the manufacturer's protocol. To detect the level of miRNA expression, reverse transcription was conducted using the EnergicScript ${ }^{\circledR}$ cDNA Synthesis kit (ShineGene Molecular Biotech, Inc., Shanghai, China). Subsequently, the RT-qPCR detection system FTC-2000 (Funglyn Biotech Inc., Toronto, Canada) was used to measure the levels of mRNA expression and miRNA with Shine-SYBR ${ }^{\circledR}$ Real Time qPCR MasterMix kit (ShineGene Molecular Biotech, Inc.). The expression of mRNA and miRNA was normalized to endogenous controls $\beta$-actin and U6 small nuclear RNA. Relative fold changes were calculated by the $2^{-\Delta \mathrm{Cq}}$ method or the $2^{-\Delta \Delta \mathrm{Cq}}$ method (24). The sequences of the primers are listed as follows: BRMS1 forward, 5'-CAGCCTCCAAGCAAAGACAC-3' and reverse 5'-GCGGCGTCGCTCATAGTC-3' and miR-125a-5p forward, 5'-GCTCCCTGAGACCCT-3' and reverse, 5'-GAGCAGGCTGGAGAA. The thermocycler conditions were as follows: $94^{\circ} \mathrm{C}$ for $4 \mathrm{~min}$, then 35 cycles of $94^{\circ} \mathrm{C}$ for $20 \mathrm{sec}, 60^{\circ} \mathrm{C}$ for $30 \mathrm{sec}$, and $72^{\circ} \mathrm{C}$ for $30 \mathrm{sec}$.

Cell transfection. The human miR-125a-5p plasmids, miR-control plasmids, anti-miR-125a-5p and anti-miR-control were designed and generated by Shanghai GenePharma Co., Ltd., Shanghai, China (Shanghai, China). The siRNA small-interfering (si)RNA (\#S1 sequence, 5'-GGAAUAAGUACGGAAUGUGA-3') that targets the BRMS1 gene was synthesized by Guangzhou RiboBio Co., Ltd., (Guangzhou, China) as previously described (25). Additionally, the coding sequences [without the 5'-untranslated region (UTR) of BRMS1] was amplified by PCR and cloned into the pcDNA3.1 (+) vector (Shanghai GenePharma Co., Ltd). The thermocycler conditions were as follows: $94^{\circ} \mathrm{C}$ for $5 \mathrm{~min}$, $94^{\circ} \mathrm{C}$ for $1 \mathrm{~min}$ and $50^{\circ} \mathrm{C}$ for $1 \mathrm{~min}$, followed by 5 cycles of $72^{\circ} \mathrm{C}$ for $1 \mathrm{~min}$, followed by 25 cycles of $94^{\circ} \mathrm{C}$ for $1 \mathrm{~min}, 65^{\circ} \mathrm{C}$ for $1 \mathrm{~min}$ and of $72^{\circ} \mathrm{C}$ for $1 \mathrm{~min}$, All constructs were verified by sequencing. The miR-125a-5p plasmids, miR-control plasmids, anti-miR-125a-5p and anti-miR-control (40 nM) were transfected using Lipofectamine ${ }^{\circledR} 2000$ reagent (Invitrogen; Thermo Fisher Scientific, Inc.) into cells in 12-well plates when $80-90 \%$ confluence was reached. A total of $24 \mathrm{~h}$ following transfection, the cells were used to perform migration and invasion assays. The RNA analysis and protein analysis were performed at $48 \mathrm{~h}$ following transfection. All sequences and primers used in this section were listed in Table I.

Cell migration and invasion analysis. The invasive and migratory capacity of the cells was estimated using Transwell chambers (diameter, $6.5 \mathrm{~mm}$, membrane pore size, $8 \mu \mathrm{m}$; Corning Incorporated, Corning, NY, USA). To conduct invasion assays, the membranes were coated with $1 \mathrm{mg} / \mathrm{ml}$ Matrigel (BD Biosciences, Franklin Lakes, NJ USA), Matrigel was not used for migration assays. The cells (migration assay, $5 \times 10^{4}$ cells; invasion assay, $1 \times 10^{5}$ cells) were suspended in $200 \mu 1$ serum-free medium, and the cells were added to the upper chamber. Then, $600 \mu 120 \%$ FBS-DMEM was added to the lower chamber. Following incubation at $37^{\circ} \mathrm{C}$ for $24 \mathrm{~h}$, the non-migrating or non-invading cells were removed with cotton swabs. Finally, invaded cells on the lower side of the filter were fixed with $4 \%$ 
Table I. All primers and sequences used in the present study.

\begin{tabular}{|c|c|}
\hline Name & Sequence $\left(5^{\prime}-3^{\prime}\right)$ \\
\hline \multicolumn{2}{|l|}{ qPCR } \\
\hline BRMS1 Forward & CAGCCTCCAAGCAAAGACAC \\
\hline BRMS1 Reverse & GCGGCGTCGCTCATAGTC \\
\hline miR-125a-5p Forward & GCTCCCTGAGACCCT \\
\hline miR-125a-5p Reverse & GAG CAG GCT GGA GAA \\
\hline$\beta$-actin Forward & TGACGTGGACATCCGCAAAG \\
\hline$\beta$-actin Reverse & CTGGAAGGTGGACAGCGAGG \\
\hline U6 snRNA Forward & CTCGCTTCGGCAGCACA \\
\hline U6 snRNA Reverse & AACGCTTCACGAATTTGCGT \\
\hline \multicolumn{2}{|l|}{ Luciferase assays } \\
\hline BRMS15'UTR(WT) Forward & CCGCTCGAGAAGCACCGATAGGCTCTGCCTC \\
\hline BRMS1 5'UTR (WT) Reverse & CGGGATCCCTGGACTCGCGGGGACTGG \\
\hline BRMS1 5'UTR(MU) Forward & CCGCTCGAGAAGCACCGATAGGCTCTGCCTC \\
\hline \multirow[t]{2}{*}{ BRMS1 5'UTR (WT) Reverse } & CGGGATCCCTGGCCTCGCGGGGACTGGAGCC \\
\hline & TCTGGCCTCACGACGGAGATTGGGACTCAGCTGCCC \\
\hline \multicolumn{2}{|l|}{ miRNAs and siRNAs } \\
\hline BRMS1 Forward & CCGCTCGAGGCCACCATGCCTGTCCAGCCTCCAAG \\
\hline \multirow[t]{2}{*}{ BRMS1 Reverse } & CGCGGGCCCTCACTTGTCGTCATCGTCCTG \\
\hline & TAGTCAGGTCCATCCGATTTTCTCTTCT \\
\hline \multirow[t]{2}{*}{ Si-BRMS1 Forward } & GATCCGGAATAAGTACGAATGTGATTCAAGAG \\
\hline & ATCACATTCGTACTTATTCTTTTTTG \\
\hline \multirow[t]{2}{*}{ Si-BRMS1 Reverse } & AATTCAAAAAAGGAATAAGTACGAATGTGATC \\
\hline & TCTTGAATCACATTCGTACTTATTCCG \\
\hline miR-125a-5p sense & GAGCUCUCCCUGAGACCCUUUAACCUGUGAAAGCUU \\
\hline miR-125a-5p antisense & AAGCUUUCACAGGUUAAAGGGUCUCAGGGAGAGCUC \\
\hline miR-125a-5p control sense & UUC UCC GAA CGU GUCACG UTT \\
\hline miR-125a-5p control antisense & ACG UGA CAC GUU CGG AGAATT \\
\hline
\end{tabular}

qPCR, quantitative polymerase chain reaction; WT, wild type; MT, mutant; BRMS1, breast cancer metastasis suppressor 1; miRNA/miR, microRNA; siRNA, small interfering RNA; UTR, untranslated region.

paraformaldehyde for $15 \mathrm{~min}$ and stained with $0.1 \%$ crystal violet (Sigma-Aldrich, Merck KGaA, Darmstadt, Germany) at $37^{\circ} \mathrm{C}$ for $30 \mathrm{~min}$. The cells were counted in five different fields with a microscope (Olympus Corporation, Tokyo, Japan).

Bioinformatics analysis. MiR-125a-5p target genes were identified using four web-based bioinformatics algorithms: microRNA.org (http://www.microrna. org/microrna/home.do),MicroCosm Targets(http://www.ebi. ac.uk/enright-srv/microcosm/htdocs/targets/v5/info.html), TargetScan Human (http://www.targetscan.org/vert_50/) and miRTar (http://mirtar.mbc.nctu.edu.tw/human/), which predict miRNA-binding sites based on complementarity to the nucleotide sequence of the miRNA (all accessed on November 10th, 2014). The algorithms used identified highly complementary sites. The results of miRTar indicated that the 5'UTR of BRMS1 binds to miR-125a-5p with a high score.

Luciferase assays. The 5'-UTR of the BRMS1 segment was amplified by PCR and inserted into the pHY-LV-Report 3.1 vector (http://www.hanyinbt.com; Shanghai, China). The thermocycler conditions were as follows: $94^{\circ} \mathrm{C}$ for $2 \mathrm{~min}$, followed by 35 cycles at $94^{\circ} \mathrm{C}$ for $20 \mathrm{sec}, 68^{\circ} \mathrm{C}$ for $40 \mathrm{sec}$ and $72^{\circ} \mathrm{C}$ for $2 \mathrm{~min}$ The mutant of the seed region of the putative miR-125a-5p binding sites in the BRMS1 5'UTR was generated using a QuikChange Site-Directed Mutagenesis kit (Agilent Technologies, Inc., Santa Clara, CA, USA). HGC27 cells $\left(8 \times 10^{3}\right.$ cells) were seeded into the 96 -well plates $24 \mathrm{~h}$ prior to transfection. A mixture of pHY-LV-5'-UTR, negative miR-control (miR-NC) or $40 \mathrm{nM}$ miR-125a-5p plasmids were co-transfected with Renilla into HGC27 cells using Lipofectamine $^{\circledR} 2000$ reagent (Invitrogen, Thermo Fisher Scientific, Inc.). $24 \mathrm{~h}$ later, the luciferase activity was measured using the Dual Luciferase assay (Promega Corporation). The Renilla reporter vector was used as an internal control to assess the efficiency of transfection. The primer sequences were listed in Table I.

Western blot assays. Total protein was extracted from gastric tissues and cells by Total Protein Extraction kit (Nanjing KeyGen Biotech Co., Ltd., Nanjing, China) according to 

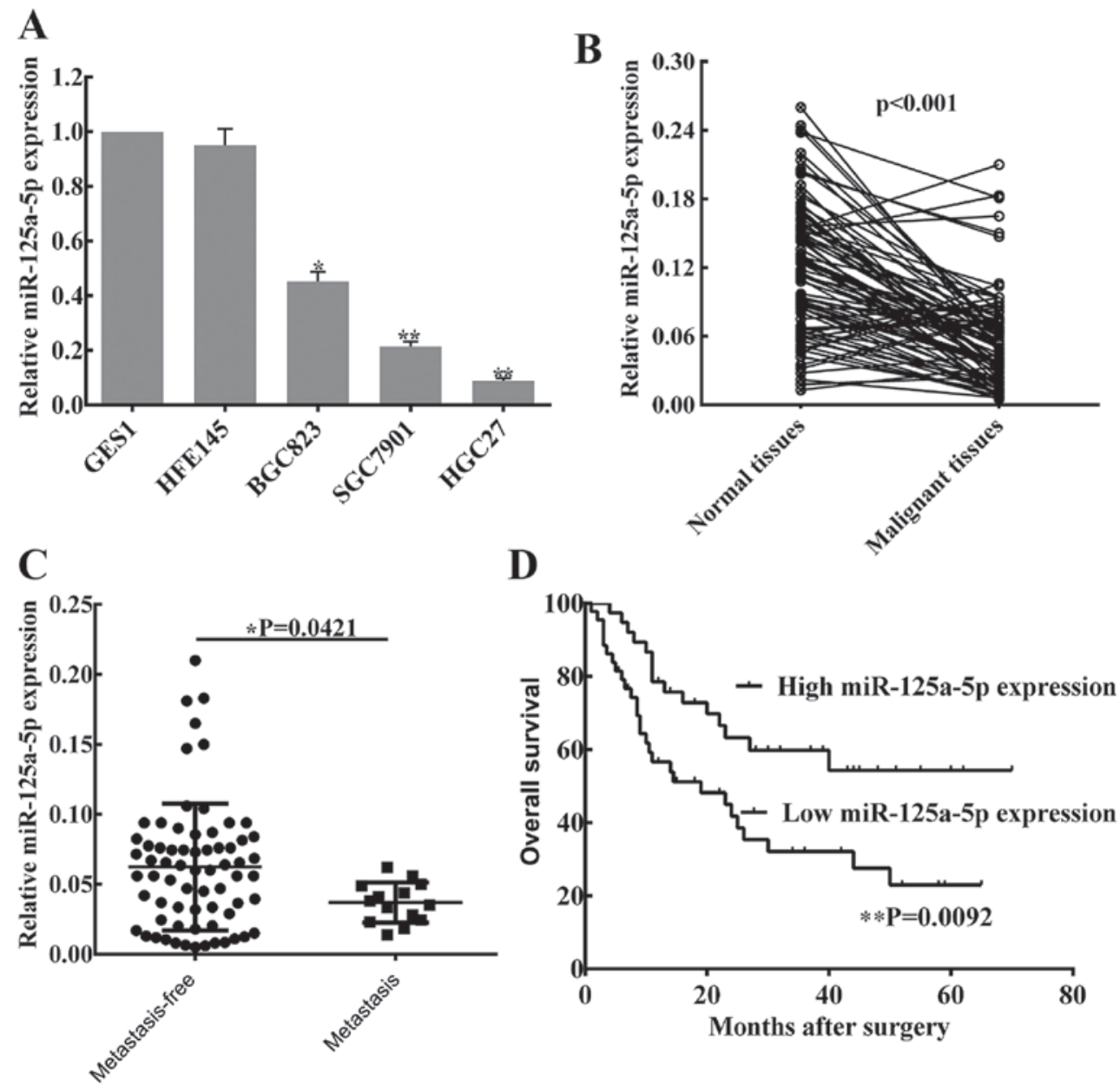

Figure 1. miR-125a-5p was downregulated in GC and associated with the capacity to metastasize. (A) The expression of miR-125a-5p in three GC cell lines (BGC823, SGC7901 and HGC27) and two normal gastric cell lines (GES1 and HFE145) was analyzed by RT-qPCR. Values are shown as the mean \pm standard deviation ( $n=3) .{ }^{*} \mathrm{P}<0.05,{ }^{* *} \mathrm{P}<0.01$ compared with GES1 and HFE145. (B) RT-qPCR results showed that miR-125a-5p expression was decreased in primary cancer tissues compared with matched normal tissues $(\mathrm{P}<0.001)$. (C) Expression of miR-125a-5p in primary GC tissues with $(\mathrm{n}=14)$ and without peritoneal metastasis $(\mathrm{n}=68)(\mathrm{P}=0.0421)$. (D) Kaplan-Meier curves indicate that the poor prognosis of $\mathrm{GC}$ patients was positively associated with miR-125a-5p expression level $(\mathrm{P}=0.0092)$. The expression of miR-125a-5p was normalized to the expression of U6 small nuclear RNA. Each experiment was repeated three times. GC, gastric cancer; miR, microRNA; RT-qPCR, reverse transcription-quantitative polymerase chain reaction.

the manufacturer's protocol and using the BAC kit (Tiangen Biotech Co., Ltd., Beijing, China) to detect the concentration of the proteins. The proteins were separated by $12 \%$ SDS-PAGE and transferred onto polyvinyl fluoride (PVDF) membranes (Bio-Rad Laboratories, Inc., Hercules, CA, USA). The membranes were blocked with $5 \%$ non-fat dried milk for $1 \mathrm{~h}$ at room temperature. Then, the membranes were incubated with the primary monoclonal antibody against BRMS1 (1:500; Sigma-Aldrich; Merck KGaA; catalog no. WH0025855M1, Merck KGaA) or $\beta$-actin $(1: 1,000$; Cell Signaling Technology, Inc., catalog no. 8H10D10) overnight at $4^{\circ} \mathrm{C}$. After washing the membranes with TBST (TBS with $0.1 \%$ Tween-20) three times, the membranes were incubated for $2 \mathrm{~h}$ at room temperature, with horseradish peroxidase-conjugated secondary antibody (goat anti-mouse IgG; Abcam, Cambridge, UK; catalog no. ab97023) and the ECL Western Blotting Analysis system (GE Healthcare, Chicago, IL, USA) was used to detect the levels of expression of the target proteins. Band intensities were quantified using Image-Pro Plus software (version, 6.0; Media Cybernetics, Inc., Rockville, MD, USA).
Statistical analysis. All experiments in the present study were repeated at least three times. The data are presented as the mean \pm standard deviation and $\mathrm{P}<0.05$ was considered to indicate a statistically significant difference. SPSS (version, 19.0; IBM Corp., Armonk, NY, USA) software was used for statistical analysis. Differences between the groups were estimated using the $\chi^{2}$, Student's t-test and one-way analysis of variance with a Student-Newman-Keuls post-hoc test. Survival was evaluated using the Kaplan-Meier method, and the correlation between miR-125a-5p and BRMS1 protein expression level was evaluated using Pearson's correlation.

\section{Results}

miR-125a-5p is downregulated in GC cells and tissues. To determine the level of miR-125a-5p expression in GC, three malignant human GC cell lines (SGC7901, HGC27 and BGC823) and two normal gastric mucosa cell lines (GES1 and HFE145), as well as 82 pairs of cancer tissues and matched normal tissues from patients with GC were used to perform RT-qPCR analysis. It was observed that the levels of miR-125a-5p were significantly 
Table II. Clinicopathological characteristics of patients with gastric cancer and miR-125a-5p expression in tumor tissues.

\begin{tabular}{|c|c|c|c|c|c|}
\hline \multirow[b]{2}{*}{ Characteristics } & \multirow[b]{2}{*}{$\mathrm{n}$} & \multicolumn{2}{|c|}{ miR-125a-5p expression $(n, \%)$} & \multirow[b]{2}{*}{$X^{2}$} & \multirow[b]{2}{*}{ P-value } \\
\hline & & Low & High & & \\
\hline \multicolumn{6}{|l|}{ Age, years } \\
\hline$<65$ & 58 & $37(72.5)$ & $21(67.7)$ & \multirow[t]{2}{*}{0.215} & \multirow[t]{2}{*}{0.643} \\
\hline$\geq 65$ & 24 & $14(27.5)$ & $10(32.3)$ & & \\
\hline \multicolumn{6}{|l|}{ Sex } \\
\hline Male & 43 & $24(47.1)$ & $19(61.3)$ & \multirow[t]{2}{*}{1.566} & \multirow[t]{2}{*}{0.211} \\
\hline Female & 39 & $27(52.9)$ & $12(38.7)$ & & \\
\hline \multicolumn{6}{|l|}{ Tumor size, cm } \\
\hline$>3.5$ & 27 & $19(32.8)$ & $8(33.3)$ & \multirow[t]{2}{*}{0.003} & \multirow[t]{2}{*}{0.960} \\
\hline$\leq 3.5$ & 55 & $39(67.2)$ & $16(66.7)$ & & \\
\hline \multicolumn{6}{|l|}{ Tumor location } \\
\hline Proximal & 17 & $12(19.4)$ & $5(25.0)$ & \multirow{3}{*}{0.303} & \multirow{3}{*}{0.859} \\
\hline Middle & 18 & $14(22.6)$ & $4(20.0)$ & & \\
\hline Distal & 47 & $36(58.0)$ & $11(55.0)$ & & \\
\hline \multicolumn{6}{|l|}{ Differentiation } \\
\hline Well & 15 & $14(25.0)$ & $1(6.2)$ & \multirow{3}{*}{3.256} & \multirow{3}{*}{0.196} \\
\hline Moderate & 26 & $22(39.4)$ & $4(25.0)$ & & \\
\hline Poor & 41 & $30(53.6)$ & $11(68.8)$ & & \\
\hline \multicolumn{6}{|c|}{ Lymph node metastasis } \\
\hline Absent & 23 & $13(21.7)$ & $10(45.5)$ & \multirow[t]{2}{*}{4.514} & \multirow[t]{2}{*}{$0.034^{\mathrm{a}}$} \\
\hline Present & 59 & $47(78.3)$ & $12(54.5)$ & & \\
\hline \multicolumn{6}{|c|}{ Peritoneal metastasis } \\
\hline Absent & 68 & $43(76.8)$ & $25(96.2)$ & \multirow[t]{2}{*}{4.705} & \multirow[t]{2}{*}{$0.030^{\mathrm{a}}$} \\
\hline Present & 14 & $13(23.2)$ & $1(3.8)$ & & \\
\hline \multicolumn{6}{|l|}{ TNM stage } \\
\hline I-II & 40 & $21(39.6)$ & $19(65.5)$ & \multirow[t]{2}{*}{5.030} & \multirow[t]{2}{*}{$0.025^{\mathrm{a}}$} \\
\hline III-IV & 42 & $32(60.4)$ & $10(34.5)$ & & \\
\hline
\end{tabular}

${ }^{a} \mathrm{P}<0.05$ was considered to be statistically significant. Statistical significance was assessed by chi-square test. miR, microRNA; TNM, tumor-node-metastasis.

lower in the GC cell lines compared with the expression in normal gastric mucosa cell lines (Fig. 1A), whereas no statistical difference in miR-125a-5p expression was indicated between the two normal gastric mucosa cell lines. In patient tissues, miR-125a-5p expression was lower compared with the matched normal tissues $(\mathrm{P}<0.01$; Fig. 1B). In addition, based on clinical progression, the expression of miR-125a-5p was markedly decreased in patients with peritoneal metastasis compared with patients without peritoneal metastasis ( $\mathrm{P}=0.0421$; Fig. 1C).

Levels of miR-125a-5p are associated with clinical pathological characteristics and prognosis in patients with GC. To investigate the associations between miR-125a-5p expression and clinical pathological characteristics, the data of 82 patients was collected from the Pathology Department of the First Affiliated Hospital of Nanchang University, and the detailed information is listed in Table II. The results showed that the expression of miR-125a-5p was significantly associated with lymph node metastasis $(\mathrm{P}=0.034)$, peritoneal dissemination
$(\mathrm{P}=0.030)$ and advanced TNM stage $(\mathrm{P}=0.025)$. However, no associations were identified between miR-125a-5p expression and other clinical pathological characteristics. Notably, Kaplan-Meier survival curves of patients with GC indicate that the overall survival rates of GC patients with low expression of miR-125a-5p was significantly shorter compared with patients with high miR-125a-5p expression ( $\mathrm{P}=0.0092$; Fig. 1D).

miR $-125 a-5 p$ regulates the invasion and migration of $G C$ cells in vitro. Previously, the association between miR-125a-5p and GC metastasis was observed (as aforementioned) and the expression of miR-125a-5p was downregulated in patients with gastric cancer, it was hypothesized that a lower miR-125a-5p expression in GC tissues was involved in invasion and metastasis of GC cells. In order to investigate the hypothesis, SGC7901 and HGC27 cells were successfully transfected with miR-125a-5p to generate an miR-125a-5p-overexpression model. The miR-control was also transfected. Invasion and migration analyses were then performed. The results 


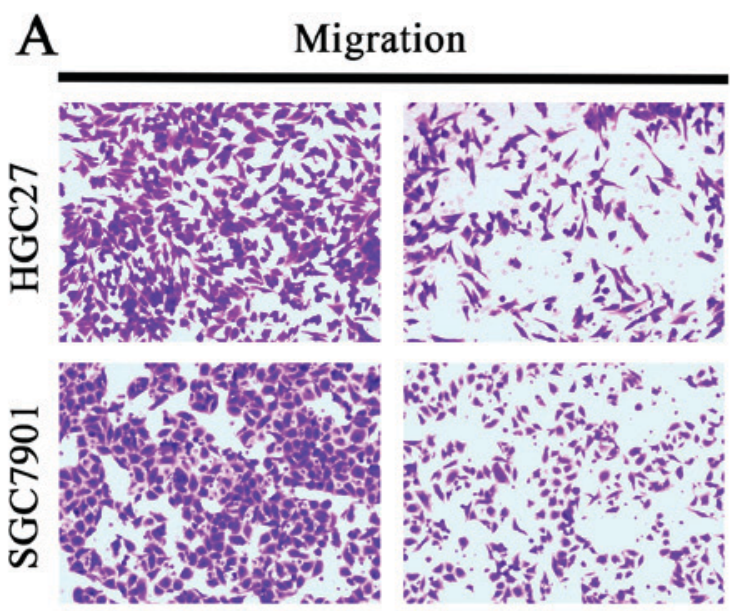

B

Invasion
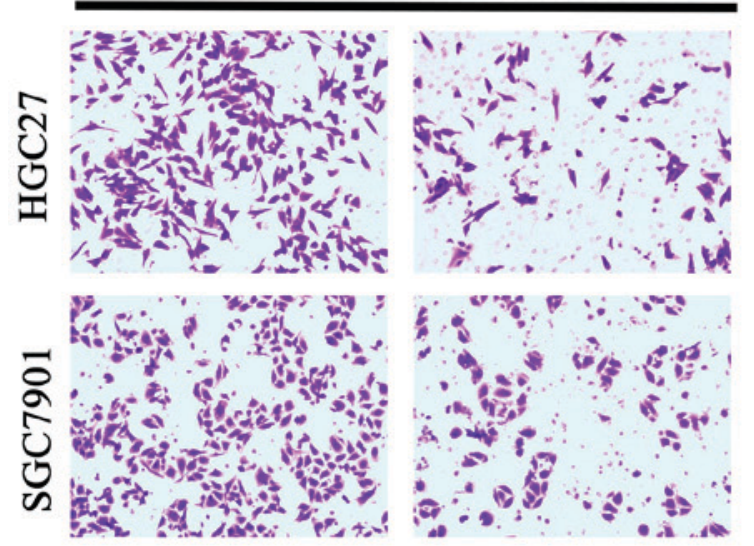

C
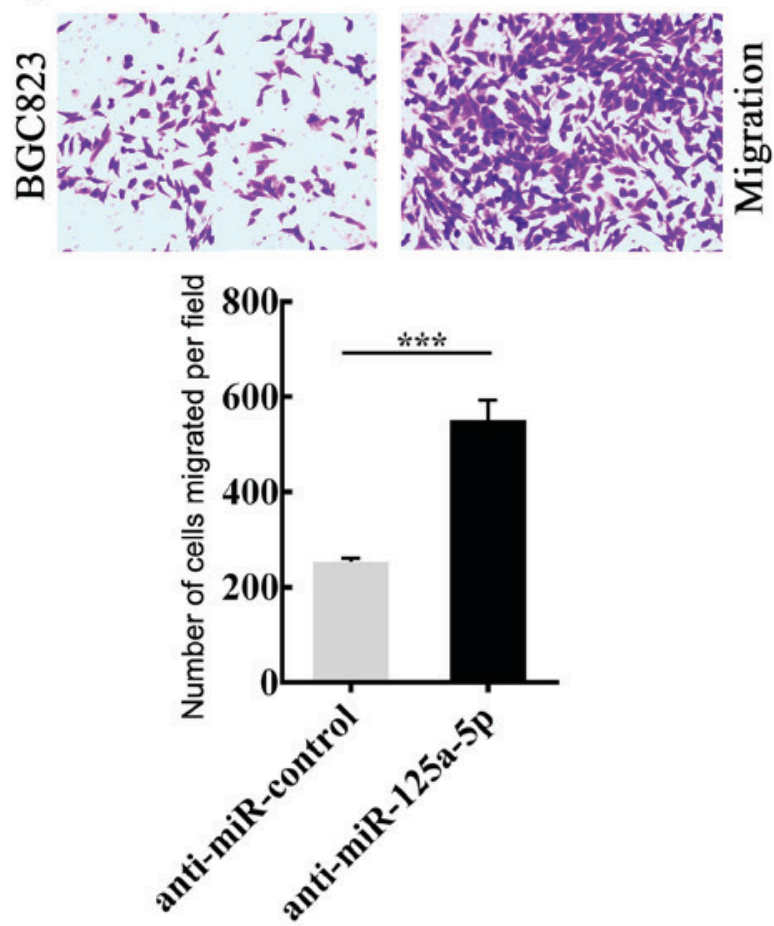
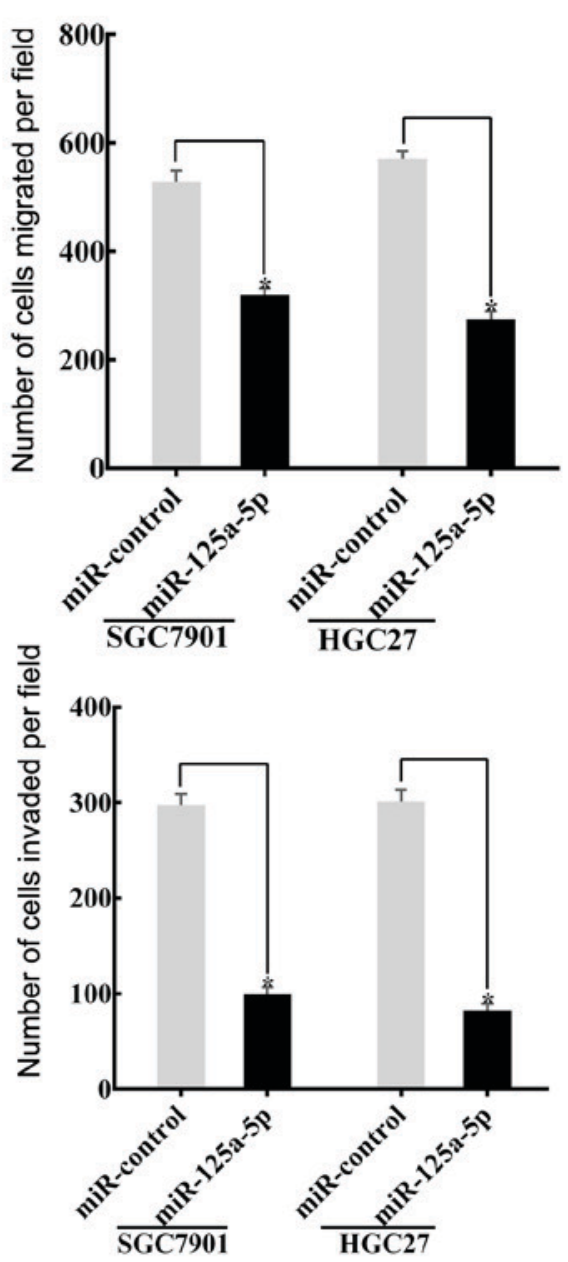

$\mathrm{D}$
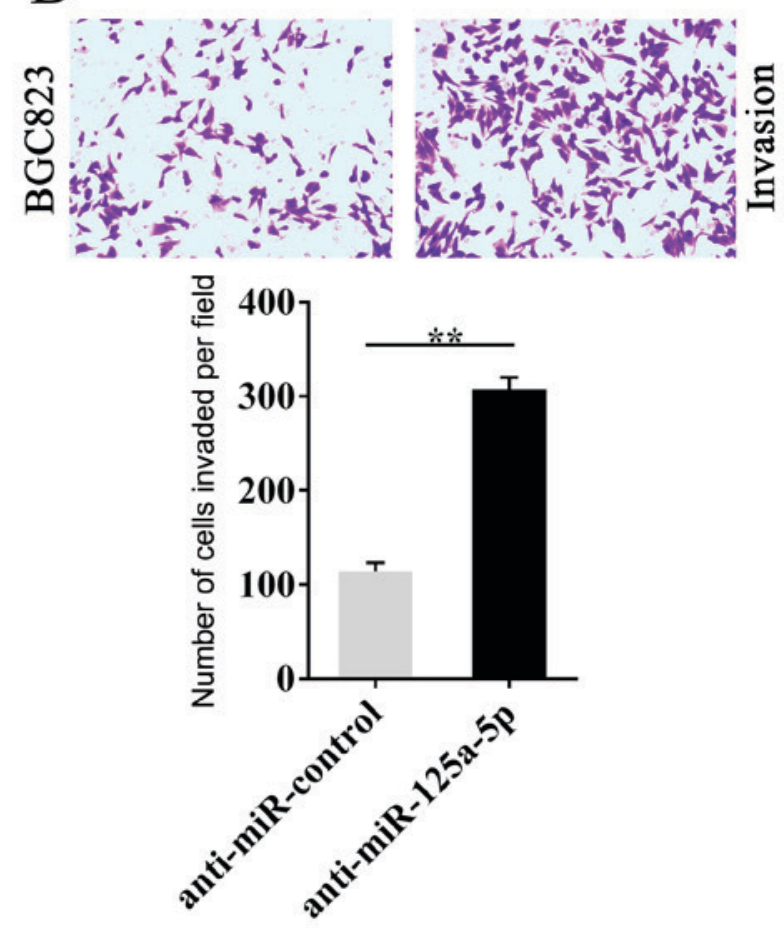

Figure 2. miR-125a-5p inhibits the migration and invasion of GC cells in vitro. (A) Transwell migration assays confirmed that the ectopic expression of miR-125a-5p inhibited the migratory ability of SGC7901 and HGC27 cells. (B) Transwell invasion assays confirmed that the ectopic expression of miR-125a-5p inhibited the invasive ability of SGC7901 and HGC27 cells. Transwell assays revealed that the knockdown of endogenous miR-125a-5p increased the (C) migratory and (D) invasive abilities of BGC823 cells. Representative micrographs and the relative number of cells are shown. The number of cells was counted from three independent experiments. The error bars represent standard deviations. Magnification, $\mathrm{x} 200$. ${ }^{*} \mathrm{P}<0.05,{ }^{* *} \mathrm{P}<0.01$ and ${ }^{* * * *} \mathrm{P}<0.001$. GC, gastric cancer; miR, microRNA. 
A

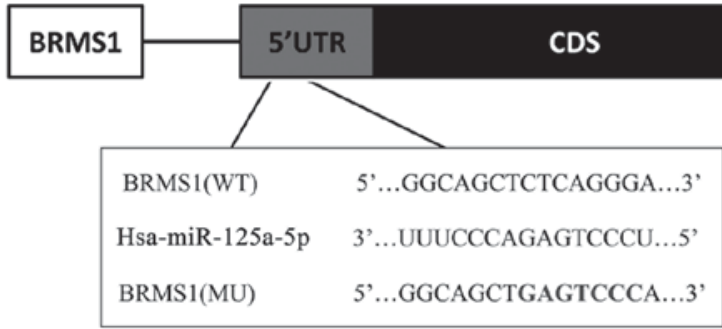

B

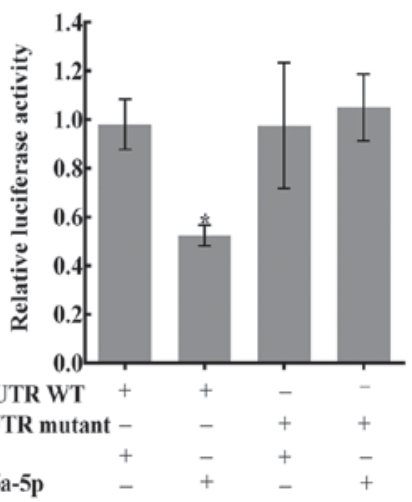

Figure 3. Confirmation of predicted binding sites between miR-125a-5p and BRMS1. (A) The bioinformatics websites (microRNA.org, MicroCosm Targets, TargetScan Human and miRTar) predicted that the 5'-UTR of BRMS1 mRNA contains the binding sequences of miR-125a-5p. (B) Dual luciferase reporter assay performed in $\mathrm{HGC} 27$ cells. The average values of normalized 5'-UTR luciferase intensity were calculated from three independent experiments. Luciferase activity was significantly decreased in the group transfected with miR-125a-5p and Wt-BRMS1-5'UTR, compared with the other three groups, "P<0.05 BRMS1, breast cancer metastasis suppressor 1; CD, coding DNA sequence; miR, microRNA; MU, mutated; UTR, untranslated region; WT, wild-type.

A

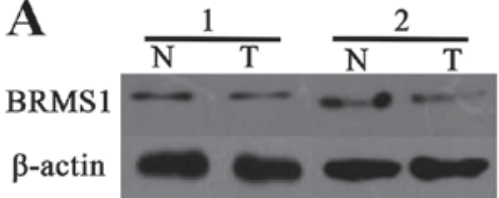

$28 \mathrm{kDa}$

$43 \mathrm{kDa}$

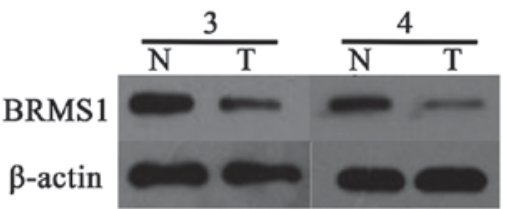

$28 \mathrm{kDa}$

$43 \mathrm{kDa}$

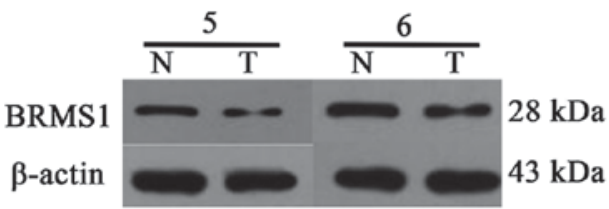

1-6;tumor sample number,T,tumor,N,normal

C

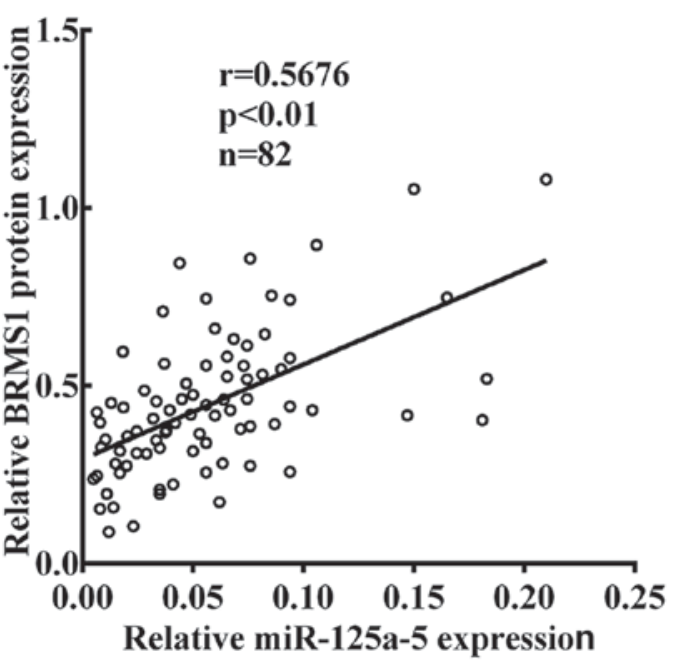

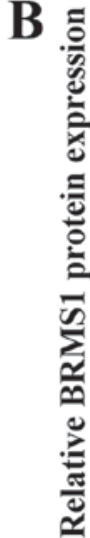
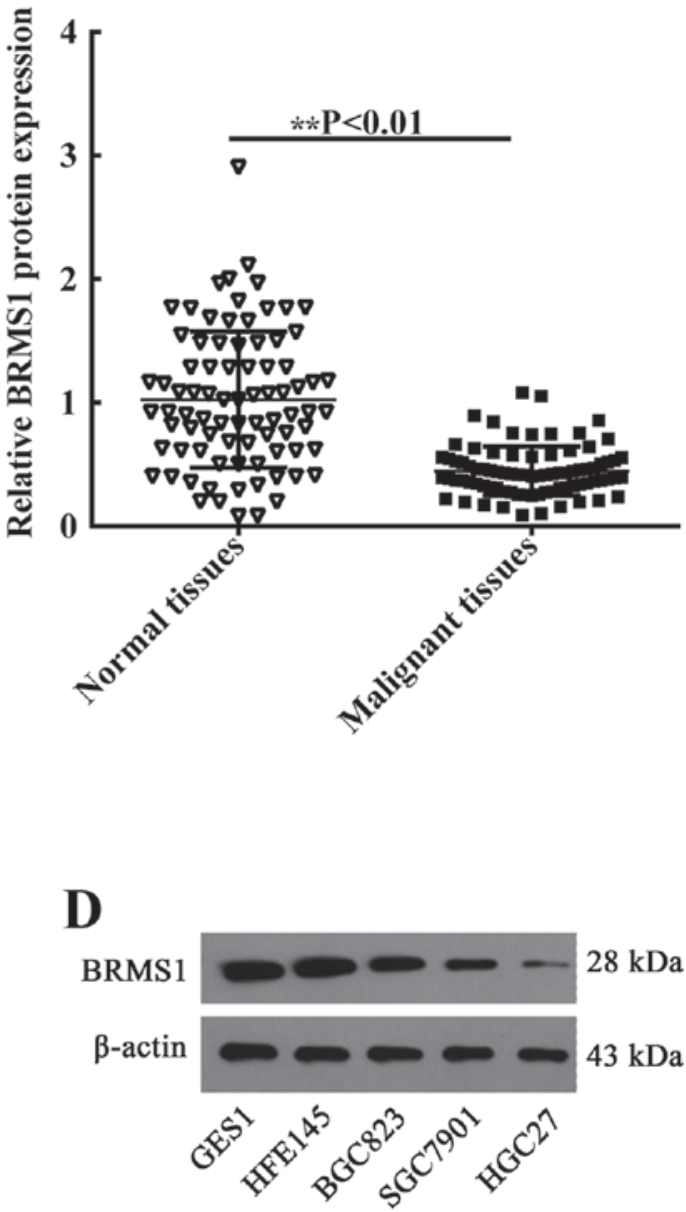

Figure 4. Expression of BRMS1 in GC tissues and cell lines, and positive correlation of BRMS1 expression with miR-125a-5p expression level. (A) Representative western blot result of GC tissues ( $n=6)$ and matched normal tissues $(n=6)$. (B) Expression of BRMS1 in $82 \mathrm{GC}$ tissues and matched normal tissues were detected by western blotting as shown by scatter plot $(\mathrm{P}<0.01)$. BRMS1 expression was normalized to $\beta$-actin expression. (C) Linear correlation analysis between the levels of BRMS1 protein and miR-125a-5p in GC tissues using Spearman's correlation analysis ( $n=82, r=0.5676$; $P<0.01$ ). (D) The levels of BRMS1 protein in three gastric cancer cell lines (BGC823, SGC7901 and HGC27) and two normal gastric cell lines (GES1 and HFE145). $\beta$-actin was used as an internal loading control. BRMS1, breast cancer metastasis suppressor 1; GC, gastric cancer; miR, microRNA; N, normal tissues; T, gastric cancer tumor tissues. 


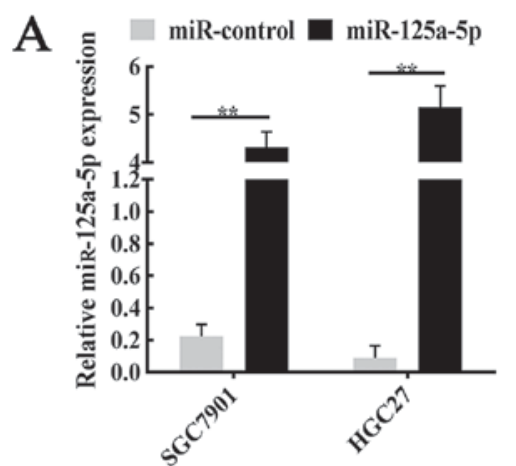

B

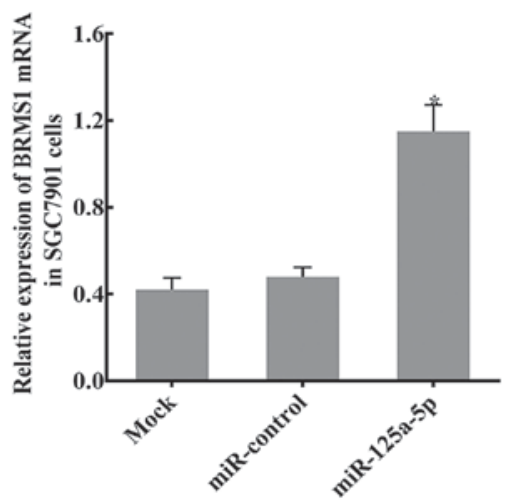

C

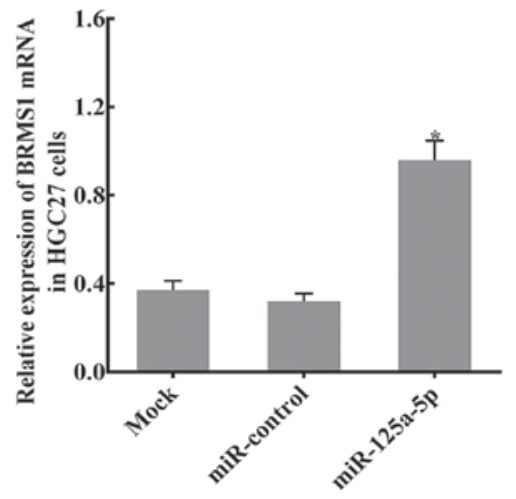

D

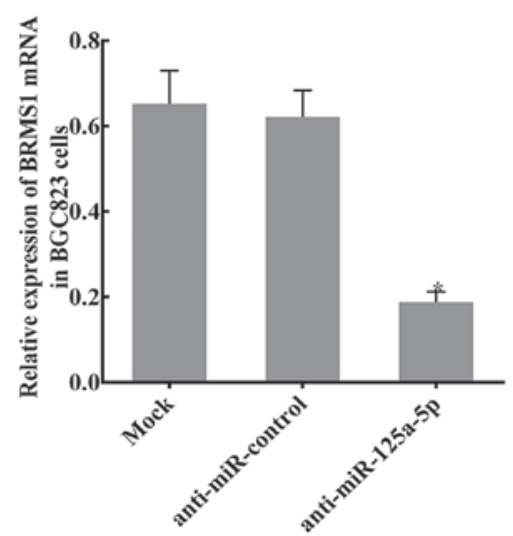

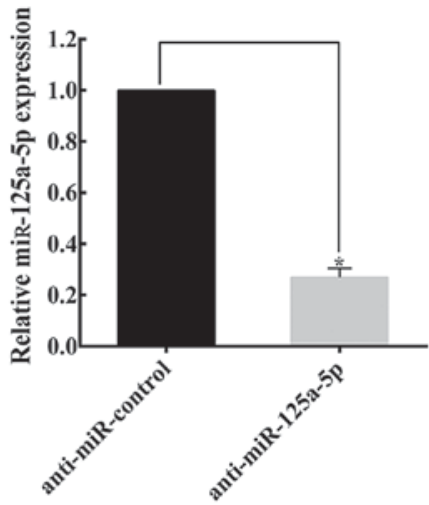

BRMS1

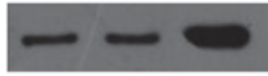

$28 \mathrm{kDa}$

$\beta$-actin

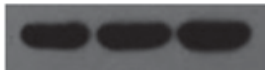

$43 \mathrm{kDa}$

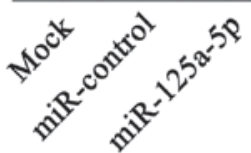

BRMS1

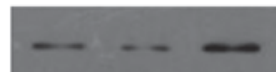

$28 \mathrm{kDa}$

$\beta$-actin

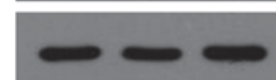

$43 \mathrm{kDa}$

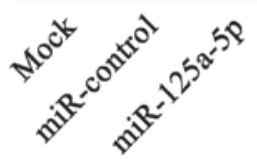

BRMS1

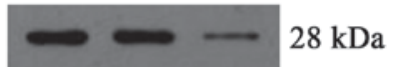

$\beta$-actin

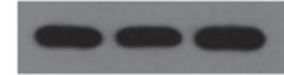

$43 \mathrm{kDa}$

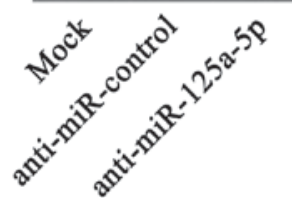

Figure 5. miR-125a-5p regulates the expression of BRMS1 in GC cell lines. (A) Compared with the expression of miR-125a-5p in miR-control-transfected controls, miR-125a-5p expression in miR-125a-5p plasmid-transfected cells was upregulated. By contrast, following the transfection of anti-miR-125a-5p, the miR-125a-5p expression in BGC823 cells was significantly suppressed. "P $<0.05,{ }^{* *} \mathrm{P}<0.01$. The expression of BRMS1 mRNA and protein in (B) SGC7901 and (C) HGC27 cells following the transfection of miR-NC or miR-125a-5p. "P<0.05 vs. Mock or miR-control groups. (D) Following transfection of BGC823 cells with anti-miR-125a-5p, the expression of BRMS1 mRNA and protein was significantly decreased compared with the expression in anti-miR-NC or mock groups. ${ }^{*} \mathrm{P}<0.05$. For reverse transcription-quantitative polymerase chain reaction assays, $\beta$-actin was used as an internal control for expression of BRMS1, and the values indicate the mean \pm standard deviation $(\mathrm{n}=3)$. For western blotting, $\beta$-actin served as an internal control. BRMS1, breast cancer metastasis suppressor 1; miR, microRNA; NC, negative control; si, small-interfering. 


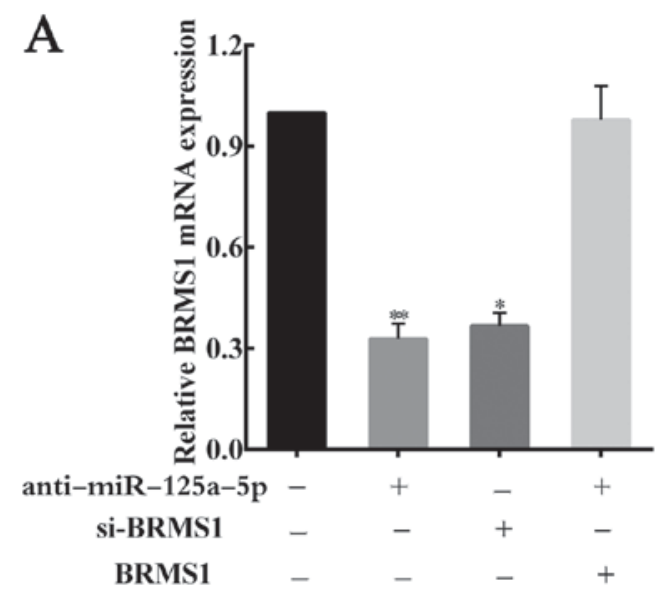

B
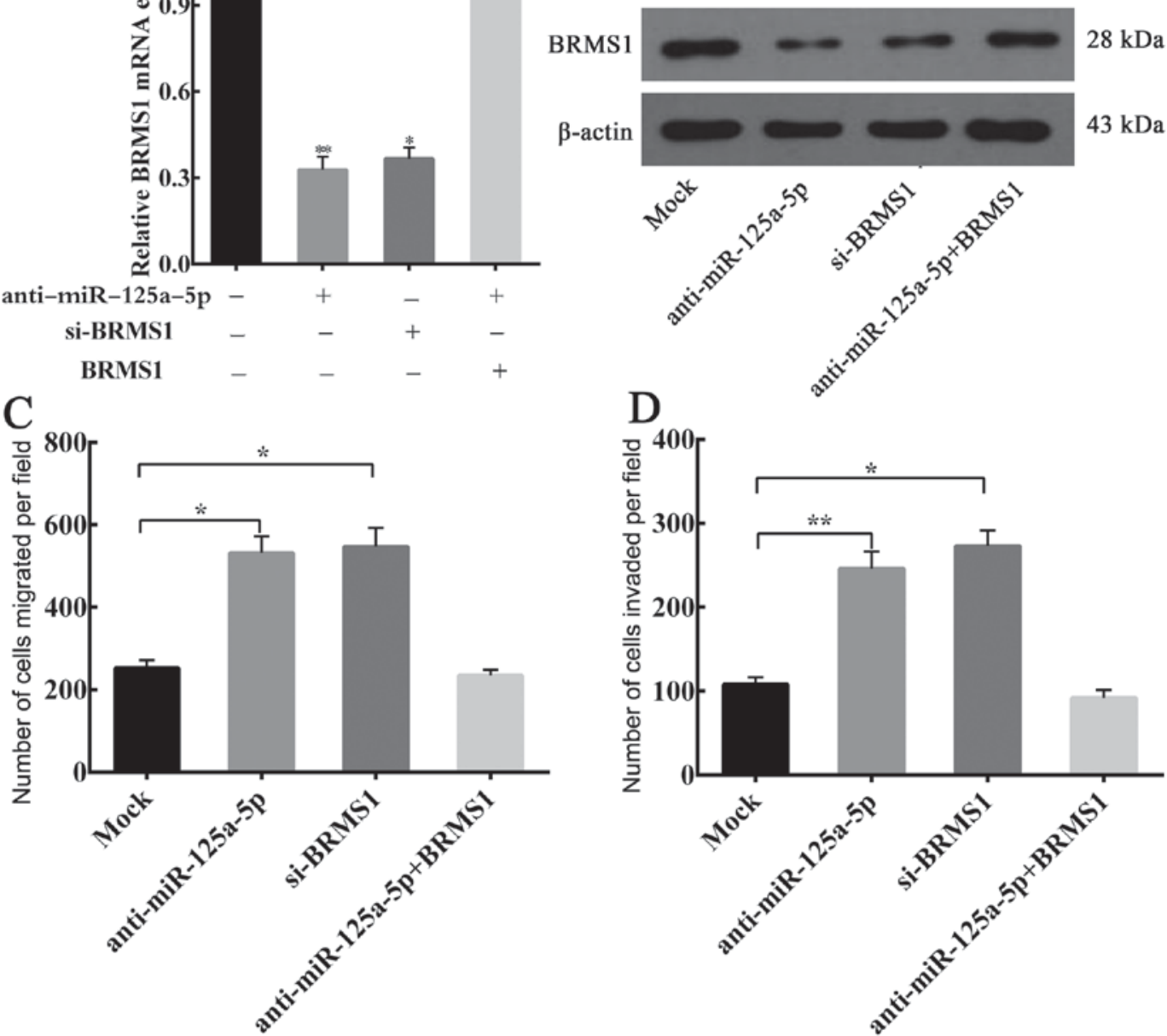

Figure 6. Involvement of BRMS1 in miR-125a-5p-induced suppression of migration and invasion of GC cells. (A) BRMS1 mRNA levels in BGC823 cells analyzed by reverse transcription-quantitative polymerase chain reaction following transfection with si-BRMS1, anti-miR-125a-5p, BRMS1 and anti-miR-125a-5p. The error bars represent standard deviation values obtained from three independent experiments. ${ }^{*} \mathrm{P}<0.05,{ }^{*} \mathrm{P}<0.01$. The value was normalized by $\beta$-actin. (B) The levels of BRMS1 protein in BGC823 cells that were transfected with si-BRMS1, anti-miR-125a-5p, and a combination of BRMS1 and anti-miR-125a-5p as detected by western blotting. $\beta$-actin served as an internal control. (C) Migration and (D) invasion assays in BGC823 cells transfected with different plasmids. Values for cell numbers represent the mean \pm standard deviation $(n=3) . ~ P<0.05,{ }^{* *} \mathrm{P}<0.01$. BRMS1, breast cancer metastasis suppressor 1; GC, gastric cancer; miR, microRNA; si-small-interfering.

showed that the migratory $(\mathrm{P}<0.05$; Fig. $2 \mathrm{~A})$ and invasive $(\mathrm{P}<0.05$; Fig. 2B) capacity of SGC7901 and HGC27 cells transfected with miR-125a-5p were significantly lower compared with those of the control group. By contrast, BGC823 cells, with high levels of endogenous miR-125a-5p expression, were transfected with anti-miR-125a-5p. Migration and invasion analyses were subsequently performed. The migration $(\mathrm{P}<0.001$; Fig. $2 \mathrm{C})$ and invasion $(\mathrm{P}<0.01$; Fig. 2D) analyses indicated that the downregulation of miR-125a-5p was able to accelerate the movement of BGC823 cells from the upper chamber to the lower chamber. The level of miR-125a-5p expression in GC cells following transfection is shown in Fig. 1. Taken together, the data was able to confirm the hypothesis that the level of miR-125a-5p expression affects the migratory and invasive abilities of GC cells.

BRMS1 is a direct target of miR-125a-5p. It has been verified that miRNAs generally regulate the expression of target genes to regulate cellular processes associated with cancer, including metastasis (26). Therefore, bioinformatics websites, including microRNA.org, MicroCosm Targets, TargetScan Human and miRTar were used to predict whether miR-125a-5p target BRMS1 genes. Bioinformatics analysis indicated that there is a putative binding site for miR-125a-5p in the 5'-UTR of BRMS1 mRNA (Fig. 3A). To investigate whether BRMS1 is an exact target of miR-125a-5p, the full-length wild-type (Wt-BRMS1-5'UTR) and mutant BRMS1 5'-UTRs (Mt-BRMS1-5'UTR) were amplified and directly fused to the pHY-LV-Report 3.1 vector downstream of the luciferase reporter gene (Fig. 3A). Then, luciferase assays were performed, and HGC27 cells were co-transfected with the vector and either with miR-NC or miR-125a-5p. Luciferase activity was significantly decreased in the group that transfected with miR-125a-5p and Wt-BRMS1-5'UTR compared with the other three groups $(\mathrm{P}<0.05$; Fig. 3B).

miR-125a-5p expression is positively correlated with the levels of BRMSI in GC. To determine the association between 
miR-125a-5p expression and BRMS1 protein levels, the expression of BRMS1 in $82 \mathrm{GC}$ patient tissues was also detected. The mean levels of BRMS1 protein were also decreased in GC samples compared with the expression in normal gastric samples (Fig. 4A and B). Subsequently, linear correlation analysis was performed to analyze the correlation between BRMS1 protein expression and the levels of miR-125a-5p in GC samples. The findings revealed that the level of BRMS1 protein was positively correlated with the levels of miR-125a-5p $(\mathrm{P}<0.01$; Fig. 4C). In addition, in order to verify that miR-125a-5p is able to regulate BRMS1 protein expression in GC cells, western blot assays were performed to detect the levels of BRMS1 protein in GC cell lines. Compared with GES1 and HFE145 cells, the expression of BRMS1 protein was significantly decreased in GC cells (Fig. 4D).

miR-125a-5p regulates BRMS1 protein expression in GC cell lines. To further verify the effects of miR-125a-5p on the regulation of BRMS1 expression, RT-qPCR and western blotting were performed to detect the relative mRNA and protein expression level in various GC cell lines (SGC7901, HGC27, BGC823). The results indicated that overexpression of miR-125a-5p (Fig. 5A) increased BRMS1 mRNA and protein expression in SGC7901 (Fig. 5B) and HGC27 cells (Fig. 5C). By contrast, marked suppression of BRMS1 expression was observed in inhibitor-treated BGC823 cells compared with untreated cells and negative control-treated cells (Fig. 5D).

miR-125a-5p inhibits migration and invasion of gastric cancer cells via BRMSI. Considering the aforementioned results, whether BRMS1 is a functional target of endogenous miR-125a-5p, which affects GC cells migration and invasion, was investigated. BGC823 cells were transfected separately with si-BRMS1 and anti-miR-125a-5p, and BRMS1 expression was analyzed by RT-qPCR and western blotting. The transfection efficiency of si-BRMS1 and anti-miR-125a-5p was detected (Fig. 6A and B). Furthermore, it was observed that there was no statistical significant difference in the ability to downregulate endogenous BRMS1 expression between anti-miR-125a-5p and si-BRMS1.

Migration and invasion assays revealed that knockdown of BRMS1 mRNA was able to significantly increase the migration and invasion of the BGC 823 cells, and similar results were observed when there is a low expression of miR-125a-5p in GC cells (Fig. 6C and D). Moreover, when BRMS1 expression was restored, it was able to counteract the inhibitory effects of anti-miR-125a-5p in BGC823 cells (Fig. 6A-D). Taken together, these results confirmed that miR-125a-5p is able to affect the migration and invasion of GC cells through regulating BRMS1 expression.

\section{Discussion}

In the present study, it was observed that miR-125a-5p is able to act as a tumor suppressor in GC. It was also revealed that downregulation of miR-125a-5p was a risk factor for lymph node and peritoneal metastasis in patients with GC.

In GC cells, upregulated miR-125a-5p expression was able to inhibit cell invasion and migration. Furthermore, to the best of our knowledge, BRMS1 was identified as a potential novel target of miR-125a-5p, and BRMS1 was associated with peritoneal metastasis in GC.

It has been hypothesized that miRNAs may function as tumor suppressors or tumor promoters, and thus perform critical roles in tumor development and progression $(9,27)$. miR-125a-5p is located at $19 \mathrm{q} 13.41$, and its downregulated expression in non-small cell lung cancer (NSCLC) was first observed in 2006 (28). A number of studies have demonstrated that the role of miR-125a-5p as a tumor-inhibiting factor in several types of tumors, including breast cancer, NSCLC and ovarian cancer (29-31). Additionally, Tong et al (32) have demonstrated that miR-125a-5p miRNA was downregulated in colorectal cancer. From these data, it may be inferred that miR-125a-5p act as a potential tumor suppressor in tumors involving the digestive tract. However, the association between miR-125a-5p and GC has not been widely investigated. In the present study, it was observed that there was a low expression of miR-125a-5p in primary tumor tissues obtained from patients with GC compared with matched normal tissues.

In addition, miR-125a-5p expression was negatively associated with lymph node metastasis, peritoneal dissemination and advanced TNM stage. In vitro experiments also indicated that overexpression of miR-125a-5p was able to suppress the migration and invasion of GC cells.

As part of the present study on how the loss of miR-125a-5p affects GC metastasis, it was confirmed that BRMS1 was a critical downstream target of miR-125a-5p. BRMS1 is a tumor suppressor (33). It has been verified that the expression of BRMS1 was regulated by miRNAs, and that it is able to inhibit the process of epithelial-mesenchymal transition and invasion in breast cancer (33). BRMS1 also regulates a network of proteins with central roles in cancer metastasis $(19,34)$. For instance, Mei et al (35) demonstrated that BRMS1 was able to inhibit the invasion of glioma cells by suppressing urokinase-type plasminogen activator, nuclear factor- $\mathrm{kB}$ and the expression and enzymatic activity of matrix metalloproteinase-2 (MMP-2). You et al (36) reported that BRMS1 is able to regulate apoptosis in NSCLC cells by modulating the activation of signal transducer and activator of transcription 3. Apart from the aforementioned signaling pathways, decreased expression of BRMS1 has also been demonstrated to induce the upregulation of human epidermal growth factor receptor 2 (HER2) in breast cancer (37). The deregulation of HER2 in cancer has been increasingly recognized, and HER2 may be an important therapeutic target in GC. A further study revealed that overexpression of miR-125a-5p was able to inhibit invasion and metastasis in GC by regulating gene HER2 (15). Based on these findings, it is hypothesized that miR-125a-5p and BRMS1 have pivotal implications in GC.

To further study the regulatory mechanisms between miR-125a-5p and BRMS1, target prediction programs were used to predict BRMS1 mRNA binding site that binds with miR-125a-5p. It was identified that the 5'-UTR of BRMS1 contained a conserved putative target site for miR-125a-5p.

In previous studies, miRNAs have been frequently reported to negatively regulate gene expression and pair with the 3'-UTR of specific target mRNAs (12-14,38-40). A number of studies have indicated that miRNAs are able to upregulate the translation of the target mRNAs and promote protein expression, by directly interacting with the 5'UTR of the mRNA (41-43). In the present study, luciferase reporter assays revealed that miR-125a-5p is 
able to directly interact with the 5'UTR of BRMS1. Exogenous expression of miR-125a-5p resulted in increased BRMS1 expression and inhibited the invasion and metastasis of GC cells. By contrast, the knockdown of miR-125a-5p induced the loss of BRMS1 expression, and upregulated the invasion and metastasis of GC cells. Restoration of BRMS1 expression resulted in the suppression of invasion and migration of GC cells. To the best of our knowledge, the results from the present study is the first to indicate that miR-125a-5p is able to directly target and promote BRMS1 expression by binding to the 5'UTR of BRMS1 mRNA.

In summary, miR-125a-5p was identified as a potential tumor suppressor in GC. Additionally, miR-125a-5p inhibits the metastatic characteristics of GC cells in vitro, including migration and invasion. Moreover, BRMS1 was identified as a potential target gene of miR-125a-5p in the development of GC. Therefore, further investigation of the miR-125a-5p-BRMS1 axis may provide novel therapeutic strategies for the treatment of GC. Further study is required to fully elucidate the mechanism of the miR-125a-5p-BRMS1 axis.

\section{Acknowledgements}

The authors thank the Departments of General Surgery and Pathology at the First Affiliated Hospital of Nanchang University for providing tissue samples and related clinical data.

\section{Funding}

The present study was supported by the National Science Foundation of China (grant nos. 81460373 and 81360362) and the 'Talent 555 Project' of Jiangxi, China.

\section{Availability of data and materials}

The datasets used and/or analyzed during the current study are available from the corresponding author on reasonable request.

\section{Authors' contributions}

ZGJ conceived the study; ZGJ, ZRL, YC, SXT and YT designed the experiments; SXT, GYZ, YL, DJL, SX and JBX identified, designed, or performed the methods; SXT, GYZ, DJL, ZBL, WYZ and PTG performed the experiments; SXT, GYZ and YC analyzed the data; and YC, SXT and ZGJ wrote the paper.

\section{Ethics approval and consent to participate}

The present study was approved by the Ethics Board of the Institute of the First Affiliated Hospital of Nanchang University (Nanchang, China). The ethics board also supervised and examined the whole process of the present study. All participants agreed to join the present study and provided written informed consent.

\section{Consent for publication}

All participants provided written informed consent for publication of the present study.

\section{Competing interests}

The authors declare that they have no competing interests.

\section{References}

1. Torre LA, Bray F, Siegel RL, Ferlay J, Lortet-Tieulent J and Jemal A: Global cancer statistics, 2012. CA Cancer J Clin 65: 87-108, 2015.

2. Yasui W, Sentani K, Sakamoto N, Anami K, Naito Y and Oue N: Molecular pathology of gastric cancer: Research and practice. Pathol Res Pract 207: 608-612, 2011.

3. Hartgrink HH, Jansen EP, van Grieken NC and van de Velde CJ: Gastric cancer. Lancet 374: 477-490, 2009.

4. Chen DL, Zhang DS, Lu YX, Chen LZ, Zeng ZL, He MM, Wang FH, Li YH, Zhang HZ, Pelicano H, et al: microRNA-217 inhibits tumor progression and metastasis by downregulating EZH2 and predicts favorable prognosis in gastric cancer. Oncotarget 6: 10868-10879, 2015.

5. Bartel DP: MicroRNAs: Genomics, biogenesis, mechanism, and function. Cell 116: 281-297, 2004.

6. Bartel DP: MicroRNAs: Target recognition and regulatory functions. Cell 136: 215-233, 2009.

7. Xiao X, Tang C, Xiao S, Fu C and Yu P: Enhancement of proliferation and invasion by MicroRNA-590-5p via targeting PBRM1 in clear cell renal carcinoma cells. Oncol Res 20: 537-544, 2013.

8. Fernandez-Santiago R, Iranzo A, Gaig C, Serradell M, Fernández M, Tolosa E, Santamaría J and Ezquerra M: MicroRNA association with synucleinopathy conversion in rapid eye movement behavior disorder. Ann Neurol 77: 895-901, 2015.

9. Shenouda SK and Alahari SK: MicroRNA function in cancer: Oncogene or a tumor suppressor? Cancer Metastasis Rev 28: 369-378, 2009.

10. Wang AM, Huang TT, Hsu KW, Huang KH, Fang WL, Yang MH, Lo SS, Chi CW, Lin JJ and Yeh TS: Yin Yang 1 is a target of microRNA-34 family and contributes to gastric carcinogenesis. Oncotarget 5: 5002-5016, 2014.

11. Wu Q, Yang Z, An Y, Hu H, Yin J, Zhang P, Nie Y, Wu K, Shi Y and Fan D: MiR-19a/b modulate the metastasis of gastric cancer cells by targeting the tumour suppressor MXD1. Cell Death Dis 5: e1144, 2014

12. Han TS, Hur K, Xu G, Choi B, Okugawa Y, Toiyama Y, Oshima H, Oshima M, Lee HJ, Kim VN, et al: MicroRNA-29c mediates initiation of gastric carcinogenesis by directly targeting ITGB1. Gut 64: 203-214, 2015.

13. Gong J, Li J, Wang Y, Liu C, Jia H, Jiang C, Wang Y, Luo M, Zhao H, Dong L, et al: Characterization of microRNA-29 family expression and investigation of their mechanistic roles in gastric cancer. Carcinogenesis 35: 497-506, 2014.

14. Li Z, Cao Y, Jie Z, Liu Y, Li Y, Li J, Zhu G, Liu Z, Tu Y, Peng G, et al: miR-495 and miR-551a inhibit the migration and invasion of human gastric cancer cells by directly interacting with PRL-3. Cancer Lett 323: 41-47, 2012.

15. Nishida N, Mimori K, Fabbri M, Yokobori T, Sudo T, Tanaka F, Shibata K, Ishii H, Doki Y and Mori M: MicroRNA-125a-5p is an independent prognostic factor in gastric cancer and inhibits the proliferation of human gastric cancer cells in combination with trastuzumab. Clin Cancer Res 17: 2725-2733, 2011.

16. Seraj MJ, Samant RS, Verderame MF and Welch DR: Functional evidence for a novel human breast carcinoma metastasis suppressor, BRMS1, encoded at chromosome 11q13. Cancer Res 60: 2764-2769, 2000

17. Wu J, Wang Y, Qiao X, Saiyin H, Zhao S, Qiao S and Wu Y: Cloning and characterization of a novel human BRMS1 transcript variant in hepatocellular carcinoma cells. Cancer Lett 337: 266-275, 2013

18. Liu Y, Mayo MW, Nagji AS, Hall EH, Shock LS, Xiao A, Stelow EB and Jones DR: BRMS1 suppresses lung cancer metastases through an E3 ligase function on histone acetyltransferase p300. Cancer Res 73: 1308-1317, 2013.

19. Slipicevic A, Holm R, Emilsen E, Ree Rosnes AK, Welch DR, Mælandsmo GM and Flørenes VA: Cytoplasmic BRMS1 expression in malignant melanoma is associated with increased disease-free survival. BMC Cancer 12: 73, 2012

20. Zhang Y, Guan J, Sun Y, Chai J, Zou T, Gong W, Zhu Z, Liu X, Hou Q and Song X: Effect of BRMS1 on tumorigenicity and metastasis of human rectal cancer. Cell Biochem Biophys 70: 505-509, 2014. 
21. Hsieh TH,Hsu CY, Tsai CF, Long CY, Chai CY,Hou MF, Lee JN Wu DC, Wang SC and Tsai EM: miR-125a-5p is a prognostic biomarker that targets HDAC4 to suppress breast tumorigenesis. Oncotarget 6: 494-509, 2015.

22. Jiang L, Huang Q, Chang J, Wang E and Qiu X: MicroRNA HSA-miR-125a-5p induces apoptosis by activating p53 in lung cancer cells. Exp Lung Res 37: 387-398, 2011.

23. Washington K: 7th edition of the AJCC cancer staging manual: Stomach. Ann Surg Oncol 12: 3077-3079, 2010.

24. Livak KJ and Schmittgen TD: Analysis of relative gene expression data using real-time quantitative PCR and the 2(-Delta Delta C(T)). Methods 25: 402-408, 2001.

25. Wu Y, Jiang W, Wang Y, Wu J, Saiyin H, Qiao X, Mei X, Guo B, Fang X, Zhang L, et al: Breast cancer metastasis suppressor 1 regulates hepatocellular carcinoma cell apoptosis via suppressing osteopontin expression. PLoS One 7: e42976, 2012.

26. Garofalo M and Croce CM: microRNAs: Master regulators as potential therapeutics in cancer. Annu Rev Pharmacol Toxicol 51: 25-43, 2011.

27. Slack FJ and Weidhaas JB: MicroRNA in cancer prognosis. N Engl J Med 359: 2720-2722, 2008.

28. Yanaihara N, Caplen N, Bowman E, Seike M, Kumamoto K, Yi M, Stephens RM, Okamoto A, Yokota J, Tanaka T, et al: Unique microRNA molecular profiles in lung cancer diagnosis and prognosis. Cancer Cell 9: 189-198, 2006.

29. O'Day E and Lal A: MicroRNAs and their target gene networks in breast cancer. Breast Cancer Res 12: 201, 2010.

30. Jiang L, Huang Q, Zhang S, Zhang Q, Chang J, Qiu X and Wang E: Hsa-miR-125a-3p and hsa-miR-125a-5p are downregulated in non-small cell lung cancer and have inverse effects on invasion and migration of lung cancer cells. BMC Cancer 10: 318, 2010.

31. Nam EJ, Yoon H, Kim SW, Kim H, Kim YT, Kim JH, Kim JW and Kim S: MicroRNA expression profiles in serous ovarian carcinoma. Clin Cancer Res 14: 2690-2695, 2008.

32. Tong Z, Liu N, Lin L, Guo X, Yang D and Zhang Q: miR-125a-5p inhibits cell proliferation and induces apoptosis in colon cancer via targeting BCL2, BCL2L12 and MCL1. Biomed Pharmacother 75: 129-136, 2015.

33. Zhang W, Qian P, Zhang X, Zhang M, Wang H, Wu M, Kong X, Tan S, Ding K, Perry JK, et al: Autocrine/paracrine human growth hormone-stimulated microRNA 96-182-183 cluster promotes epithelial-mesenchymal transition and invasion in breast cancer. J Biol Chem 290: 13812-13829, 2015.

34. Hurst DR: Metastasis suppression by BRMS1 associated with SIN3 chromatin remodeling complexes. Cancer Metastasis Rev 31: 641-651, 2012.
35. Mei P, Bai J, Shi M, Liu Q, Li Z, Fan Y and Zheng J: BRMS1 suppresses glioma progression by regulating invasion, migration and adhesion of glioma cells. PLoS One 9: e98544, 2014.

36. You J, He X, Ding H and Zhang T: BRMS1 regulates apoptosis in non-small cell lung cancer cells. Cell Biochem Biophys 71: 465-472, 2015.

37. Roberts MR, Hong CC, Edge SB, Yao S, Bshara W, Higgins MJ, Freudenheim JL and Ambrosone CB: Case-only analyses of the associations between polymorphisms in the metastasis-modifying genes BRMS1 and SIPA1 and breast tumor characteristics, lymph node metastasis, and survival. Breast Cancer Res Treat 139: 873-885, 2013.

38. Kim HS, Lee KS, Bae HJ, Eun JW, Shen Q, Park SJ, Shin WC, Yang HD, Park M, Park WS, et al: MicroRNA-31 functions as a tumor suppressor by regulating cell cycle and epithelial-mesenchymal transition regulatory proteins in liver cancer. Oncotarget 6: 8089-8102, 2015 .

39. Xu J, Wang T, Cao Z, Huang H, Li J, Liu W, Liu S, You L, Zhou L, Zhang $\mathrm{T}$ and Zhao Y: MiR-497 downregulation contributes to the malignancy of pancreatic cancer and associates with a poor prognosis. Oncotarget 5: 6983-6993, 2014.

40. Wang Q, Huang Z, Guo W, Ni S, Xiao X, Wang L, Huang D, Tan C, Xu Q, Zha R, et al: microRNA-202-3p inhibits cell proliferation by targeting ADP-ribosylation factor-like $5 \mathrm{~A}$ in human colorectal carcinoma. Clin Cancer Res 20: 1146-1157, 2014.

41. Orom UA, Nielsen FC and Lund AH: MicroRNA-10a binds the 5'UTR of ribosomal protein mRNAs and enhances their translation. Mol Cell 30: 460-471, 2008.

42. Tsai NP, Lin YL and Wei LN: MicroRNA mir-346 targets the 5'-untranslated region of receptor-interacting protein 140 (RIP140) mRNA and up-regulates its protein expression. Biochem J 424: 411-418, 2009.

43. Vasudevan S, Tong Y and Steitz JA: Switching from repression to activation: microRNAs can up-regulate translation. Science 318: 1931-1934, 2007 